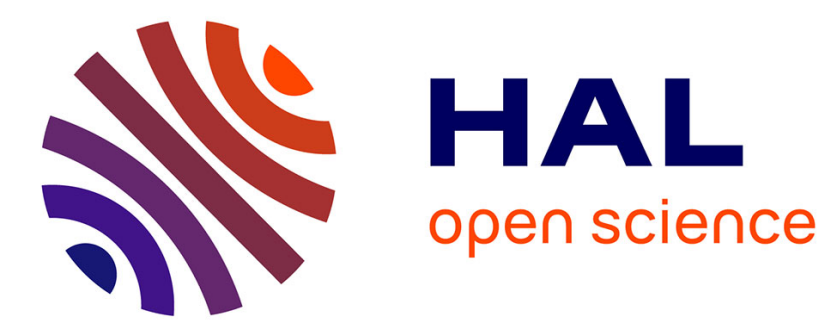

\title{
Factors driving the discovery and utilization of a newly available area by African elephants
}

\author{
Anne Pandraud, Adrian M. Shrader, Craig Sholto-Douglas, Simon
}

Chamaillé-Jammes

\section{- To cite this version:}

Anne Pandraud, Adrian M. Shrader, Craig Sholto-Douglas, Simon Chamaillé-Jammes. Factors driving the discovery and utilization of a newly available area by African elephants. Journal of Tropical Ecology, 2020. hal-03015498

\section{HAL Id: hal-03015498 \\ https://hal.science/hal-03015498}

Submitted on 19 Nov 2020

HAL is a multi-disciplinary open access archive for the deposit and dissemination of scientific research documents, whether they are published or not. The documents may come from teaching and research institutions in France or abroad, or from public or private research centers.
L'archive ouverte pluridisciplinaire HAL, est destinée au dépôt et à la diffusion de documents scientifiques de niveau recherche, publiés ou non, émanant des établissements d'enseignement et de recherche français ou étrangers, des laboratoires publics ou privés. 
13 Corresponding author

14 Anne Pandraud; Phinda Private Game Reserve, 1 Old Sodwana Bay Road 3960 Hluhluwe, South Africa;

15 pandraudanne@gmail.com. 16-digit ORCID: 0000-0002-2831-7283.

18 Acknowledgments

19 We are thankful to Phinda Private Game Reserve for providing logistical support and for sharing their historical

20 data. S. Chamaillé-Jammes was partially supported by grant ANR-16-CE02-0001-01 from the French 'Agence

21 Nationale de la Recherche'. An anonymous reviewer provided useful suggestions.

22 
2 Abstract

3 For large mammals, area expansion is a key conservation measure to prevent species' decline and extinction. Yet,

4 its success depends on whether animals discover and later use these areas. Here, using GPS data, we investigated

5 how herds of elephants detected and used an area made available to them after the removal of a fence. We

6 studied the elephants' behaviour before and after the fence removal, accounting for seasonal changes in

7 movement patterns. In contrast to previous studies, herds visited the newly available area within a month of the

8 fence removal, and the maximum distance they moved into the new area was reached between five and nine

9 months after the fence removal. Yet, elephants did not preferentially visit the new area at night. By the second

10 year, all herds had shifted their seasonal home ranges and incorporated the new area, in contrast to a previous

11 range expansion event. Our analyses show that the regular proximity of elephants to the original fence, and the

12 fact that the new area was generally composed of preferred habitats of the elephants, likely explained the rapid

13 discovery and use of the area. Our study improves our understanding of animal exploration and the role of

14 habitat quality, and thus may improve range expansion and corridor programmes.

15

16 Key-words

17 Discovery, landscape exploration, habitat selection, Loxodonta africana, protected area expansion

18 
3 Introduction

Space is critical to the conservation of most species, and this is particularly true for large mammals that

5 tend to roam over large areas (e.g. Fryxell \& Sinclair, 1988, Mueller et al. 2011). However, in human-modified

6 landscapes, space has become a limiting factor for many species (Tucker et al. 2018). To overcome species'

7 decline and extinction (Cardillo et al. 2004, Harris et al. 2009) some conservation efforts have focussed on

8 preventing the destruction of existing natural areas through the creation of new protected areas (Naughton-

9 Treveset al. 2005). For example, over the last four years 30,000 sites were added to the World Database on

10 Protected Areas (UNEP-WCMC 2018). In addition, range expansion via corridors (e.g. Douglas-Hamilton et al.

11 2005, Osborn \& Parker 2003), protected area expansion (e.g. Druce et al. 2007), and the amalgamation of

12 protected areas (e.g. fence removal between Kruger National Park (South Africa) and Limpopo National Park

13 (Mozambique) in 2002) are key conservation measures.

However, despite the growing use of the strategy of protected area expansion, we know very little about

15 how animals detect and later use these new areas. Thus, we are unsure just how successful these conservation

16 measures may be. Discovery of newly available areas likely depends on factors such as the proximity of the

17 animals to these areas and their exploratory behaviour (Druce et al. 2007). Yet, this latter aspect remains poorly understood (e.g. Mettke-Hofmann et al. 2002, Switzer 1993).

Exploration might be limited in favourable environments (e.g. Mettke-Hofmann et al. 2002, Switzer

20 1993) or, conversely, when overall conditions in an animal's range are bad (e.g. Larkin et al. 2004, van Moorter

21 et al. 2013). Generally, animals show relatively strong site fidelity that limits exploration and may even delay the

22 discovery of new places (e.g. de Knegt et al. 2010, Switzer 1993). For instance, black rhinoceros (Diceros

23 bicornis) have been found shown to be slow to colonize a harvested neighbour's range (Linklater et al. 2010). In

24 central Idaho, introduced grey wolves (Canis lupus) limited their movements to within a small core area the first

25 year after their reintroduction, only after that took a long time before exploring beyond this core (Bangs \& Fritts

26 1996). Similarly, newly introduced black bear (Ursus americanus) limited their movements and even tried to

27 move back to their previous range (Eastridge \& Clark 2001).

African elephant (Loxodonta africana) populations provide an interesting case study in the context of

29 range expansion. Space is critical for these large, wide-ranging species (Owen-Smith 1988). As such, many

30 populations have been exposed to area expansion, often either to: (1) allow for population expansion (e.g. fence 
1 removal, Druce et al. 2007), or (2) reduce the impact of dense elephant populations on the landscape (Biggs et al.

2 2008). Elephants have shown contrasting responses when faced with one of these different expansion measures.

3 For instance, elephants moved rapidly into new areas after the fence was removed between Kruger and Sabi

4 Sand Wildtuin and migration paths were re-established (Grant et al. 2008). In contrast, when the fence between

5 Marakele National Park and Marakele Pty Ltd was removed in 2001, it took elephants two years before they

6 visited the newly available area (Bezuidenhout 2004). Similarly, when the boundary fence between Phinda

7 Private Game Reserve and one neighbouring reserve was removed in 2004, it took resident family groups

8 between six and nine months to venture into the new area (Druce et al. 2007). Moreover, only one herd expanded

9 its core range to incorporate this newly available area despite its relatively small size $(3,850$ ha; Druce et al.

10 2007). However, despite these studies, we still have a poor understanding of the factors associated to elephants'

11 discovery of a newly opened area and which factors influence their response to area expansion. In fact little

12 attention has been given to the factors (e.g. spatial distribution, diet and habitat preferences) that underlie

13 elephants' response to range expansion measures.

Here we studied the response of African elephant breeding herds to the removal of a fence between

15 Phinda Private Game Reserve and a neighbouring reserve, in South Africa. We did so by using data from GPS

16 collars fitted on each matriarch. We describe the discovery and use of the newly available area, but unlike

17 previous studies (Druce et al. 2007) we also analyse elephant behaviour (habitat selection, distribution in relation

18 to the fence) before the fence removal to understand the factors that could have facilitated the discovery and use

19 of the new section, accounting for seasonal changes in movement patterns.

We hypothesised that the proximity to the new section might determine how long it takes herds to find

21 and use the section. Thus, we expected herds regularly close to the previous fence to discover and explore this

22 section quicker than herds which were usually located farther away. For instance, it has been shown that

23 elephants use their sense of smell to make foraging decisions (Schmitt et al. 2018) and being close to the new

24 area might increase the chances of smelling a new foraging place. Because animals have habitat preferences (e.g.

25 de Knegt et al. 2010, Switzer 1993), we expected that elephants would move more rapidly into areas containing

26 the preferred habitats compared to those with the less preferred habitats.

27

28 Methods

29 Study area 
1 Phinda Private Game Reserve (referred to as Phinda from here on) (16,826 ha) is located within the Mun-Ya-

2 Wana Conservancy (MYW), Kwa-Zulu-Natal Province, South Africa (2751'30'’S, 32॰19'00'’E) (Fig. 1)

3 Phinda comprises nine different vegetation types across a mosaic of savanna woodlands and sand forests (Supp.

4 Appendix 1.) (Druce et al. 2007, Slotow \& Page 2002). The climate is subtropical with annual temperatures

5 ranging from $10{ }^{\circ} \mathrm{C}$ to $35^{\circ} \mathrm{C}$ and a mean annual rainfall of $700 \mathrm{~mm}$ and a standard deviation of $\pm 230 \mathrm{~mm}(1995$ -

6 2018). Rain falls in every month of the year but the summer wet season (all months with $>50 \mathrm{~mm}$ of

7 precipitation. Knoch \& Schulze 1957) runs from October to March (mean rainfall of $89 \mathrm{~mm}$ ), while the winter 8 dry season runs from April to September (mean rainfall of $27 \mathrm{~mm}$ ).

9 Between 1993 and 2011 more properties were added to MYW which currently comprises three private 10 game reserves that were initially separated by fences (Fig. 1). Elephants were introduced into Phinda between 111992 and 1994 (Druce et al. 2007, Slotow \& Page 2002) from the Kruger National Park (Slotow \& Page 2002).

12 Currently the population is estimated to be around 110 elephants, divided in six breeding herds of $\sim 10$

13 individuals each, and various sized bachelor herds (ranging from two to five individuals each) incorporating the 14 reserve's 25 males. Elephants are free ranging within MYW.

15 On 4 October 2017, which correspond to the beginning of the wet season, the boundary fence between

16 Phinda and the neighbouring Lulubush Game Reserve (LGR) (1,612 hectares) was removed. As a result, MYW

17 now contains 243 natural and artificial waterpoints, with 21 in LGR. Most of the LGR waterpoints are man-made but none of them are supplied by a pump. In the dry season, water is available in MYW in three non-perennial

19 rivers and six artificial water sources that are maintained during the dry season.

21 Data

22 We collected elephant positional data every four hours using GPS/GSM manufactured by African Wildlife

23 Tracking fitted to the matriarch of each of the six breeding herds. Collars were put on two years prior to the start 24 of our study by a trained veterinarian after the elephant had been tranquilised from an helicopter. The movement 25 of these females was assumed to represent the movement of the whole breeding herd to which they belonged 26 (Druce et al. 2007). For each of the herds, we collected location data one year before and one year after the fence 27 removal. However, for one herd (FH1), positional data were only available from after the removal of the fence. 28 As a result, we could only use the data from this herd in the analysis focusing on elephant behaviour post fence 29 removal. 


\section{Elephants' response to an area expansion}

Identifying independent herds

2 Field observations indicated that some of the herds spent a significant amount of time together. As these herds

3 would not provide independent information, we considered two herds to be "together" when the distance

4 between the herds, obtained from locations acquired less than $30 \mathrm{~min}$ apart, was less than $250 \mathrm{~m}$. Results (Supp.

5 Appendix 2) showed that two herds (FH5 and FH2) were together more than $68 \%$ of the time. As these herds

6 would provide pseudo-replicated information, we randomly selected the data from herd FH5 in the analyses.

7 Nevertheless, we explored whether using the data from herd FH2 would change the results and they did not.

8 Thus, we only used the data from herd FH5. We did not include the data from both herd when they were apart

9 because the sample size of $\mathrm{FH} 2$ alone was too small to be representative of the herd's behaviour and to bring a

10 significant information to the other data.

11

\section{Habitat selection}

13 We first determined the habitat composition of the newly available LGR section using a vegetation map (Supp.

14 Appendix 1). From this, we defined seven different vegetation types: (1) palm veld, (2) mixed acacia and

15 lebombo woodlands, (3) floodplain grasslands, (4) bush clump thickets, (5) mixed zululand lowveld savanna, (6)

16 riparian, and (7) sand forest and sandveld woodlands. As the elephants are fenced out of a large part of the sand

17 forest we grouped sand forest and sandveld woodlands into one habitat type. This avoided creating instability in 18 estimates due to the small number of locations in the sand forest. Then, to understand whether the available

19 habitats in the LGR were those preferred by elephants, we analysed the habitat selection of the elephants before

20 the fence removal, for the wet and dry season separately. We calculated, for each herd and each season, the

21 selection ratio $\left(\mathrm{SR} ; \mathrm{SR}=\right.$ Prop $_{\text {used }} /$ Prop $_{\text {available}}$ ) and the associated confidence intervals (confidence limits: $2.5 \%$

22 and 97.5\%) (Chamaillé-Jammes 2019, Manly 2002) for each habitat. We estimated Prop used using the actual GPS

23 locations of elephants, and Propavailable by plotting 2,500 random points within each herd seasonal home range.

\section{Individual herd exploratory behaviour}

26 We studied the temporal dynamics of exploration and use of the newly opened section during the wet season

27 following the removal of the fence. In particular, we studied how long it took the elephant herds to enter the

28 section. For each herd, we measured the time to first visit as the time between the fence removal and the first

29 location of the herd at least $50 \mathrm{~m}$ (to account for potential GPS error) within the new section. We investigated

30 whether the time to first visit was related to: (1) the distance at which elephants were to the fence the day the 
1 fence was removed, (2) the proportion of time elephants spent within $100 \mathrm{~m}$ of the fence during both the wet and

2 the dry seasons a year before the fence removal, and (3) the average return time to within $100 \mathrm{~m}$ of the fence in

3 both seasons a year before the fence was removed.

$4 \quad$ We calculated how far herds ventured into the newly opened section during their first visit and

5 measured the maximum distance travelled within this section from the date of the first visit (Druce et al. 2007).

6 Finally, we determined whether the elephant herds used the new section more at night (18h30 to $05 \mathrm{~h} 30)$ as found

7 in another study (Druce et al. 2007) or during the day (05h30 to 18h29) by comparing the mean number of

8 locations within the section during these periods.

10 Home-range shifts

11 We studied whether the opening of the LGR affected the size and location of the seasonal home ranges of each elephant herd. As the fence removal occurred at the beginning of the wet season, we computed wet and dry

13 season home ranges before the fence removal, and the wet and the dry season home ranges after the removal.

14 The overall study site is fenced, which creates limitation to elephant movement that should be accounted for

15 when estimating home ranges. We therefore used local convex hull (LoCoH) nonparametric kernel method to 16 estimate home ranges as they naturally allow for hard boundaries in home ranges (Getz et al. 2007). We defined 17 a home range as the area within the $90 \%$ isopleth, estimated following the 'fixed number of points' approach (k18 LoCoH, Getz et al. 2007), with k chosen following the "rules of thumb" proposed by Getz et al. (2007). Selected 19 values of $k$ ranged between 33.0 and 46.5 (the values are reported in the caption of Table 4).

To determine whether elephants had relocated or extended their home ranges after the fence removal, we

21 first determined whether there were seasonal changes in home ranges irrespective of the range expansion event.

22 We did this by computing the overlap between wet and dry season home ranges, in the year before the fence 23 removal, to measure what proportion of the wet season home range was in the dry season home range. Once we 24 had done this, we then computed the proportion of the pre-removal wet and dry season home ranges which remained in the wet and dry season home ranges after the fence was removed. Finally, we assessed whether any post fence removal changes to the seasonal home ranges altered the seasonal habitat composition of the home ranges. We did this by estimating, for each herd, the percentage of each vegetation type included in their dry and wet season home range separately, a year before and a year after the fence removal (results are reported in Supp. Appendix 3). 
1 Results

Habitat selection

3 Although elephant habitat selection prior to the fence being removed was variable (Fig. 5), the herds preferred

4 the 1) palm veld, and 2) sandveld woodlands and sand forest habitat types (Fig. 5), with FH3, FH4 and FH5's

5 seasonal home ranges dominated by these habitat types prior to the fence being removed. Moreover, these

6 habitats respectively accounted for on average $21 \%$ and $46 \%$ of their dry season home range and on average

$7 \quad 19 \%$ and $35 \%$ of their wet season home range (Supp. Appendix 3). Palm veld, sandveld woodlands and sand

8 forest were also the most available habitats in FH3, FH4 and FH5's seasonal home ranges before the fence

9 removal (Supp. Appendix 4). Only FH6's seasonal home ranges were dominated by mixed acacia woodlands,

10 with $65 \%$ included in the dry season home range and $76 \%$ in the wet season home range (Supp. Appendix 3 ).

11 The LGR comprised five different vegetation types: $62 \%$ sandveld woodlands and sand forest, $27 \%$ palm

12 veld, $10 \%$ mixed acacia woodlands, and 1\% riparian forest. As these habitats were key in the herds' home ranges

13 prior to the fencing being removed, it suggested that the herds would find suitable habitats in the LGR after the

14 fence separating the properties was taken down.

\section{Exploratory behaviour}

17 All of the elephant herds visited the newly opened section soon after the fence was removed (Fig. 2). Herd FH4 visited five days after the removal, while three other herds (FH1, FH3 and FH5) went into the section between

19 nine and 13 days after the fence was removed. Finally, FH6 visited the section 34 days after the fence was 20 removed.

Although the herds had spent only between 0.1 and $2.0 \%$ of their time within $100 \mathrm{~m}$ of the LGR (Table 1), they were regularly within $100 \mathrm{~m}$ during the dry season preceding the removal of the fence. For example, FH4 was within $100 \mathrm{~m}$ of the fence on average every 6.8 days, FH5 every 10.1 days, and FH3 every 19.1 days. This was far more frequent than in the preceding wet season, when the herds were $<100 \mathrm{~m}$ of the fence somewhere between 11 and 170 days (Table 1). The day of the fence removal, all the herds were approximately $11 \mathrm{~km}$ from the fence, and a negative relationship appeared between the time taken to go into LGR after the fence removal and the percentage of time spent within $100 \mathrm{~m}$ of the previous fence (Fig. 3). 
1 relatively close to the boundary (309 $\mathrm{m}$ and $312 \mathrm{~m}$ respectively). During this period, the others remained

2 between $1.3 \mathrm{~km}$ and $2.1 \mathrm{~km}$ from the boundary, until they moved directly into the LGR (Fig. 2).

During their first visit into the LGR, all of the herds stayed less than eight hours, and three herds less than

4 five hours, in the LGR. Upon entering, the herds only travelled between $278 \mathrm{~m}$ and $672 \mathrm{~m}$ into the LGR (Table

5 2). Only, herd FH6, which was the last one to enter LGR, travelled a distance greater than $1 \mathrm{~km}$ into the LGR

6 during its first entry (Table 2). Ultimately, it took nine months for all the herds to travel $3.5 \mathrm{~km}$ into the LGR

7 (Table 2).

8 During the wet season following the removal of the fence (i.e. the first six months after the removal), the

9 elephants went into the LGR regularly. The average period between visits for the herds FH1, FH3, FH4 and FH5

10 was between 0.48 and 0.60 days. For FH6, it was every two days (Fig. 2). However, FH6 was regularly in the

11 new area between the $7^{\text {th }}$ of November and the $13^{\text {th }}$ of December with on average, 0.51 days between visits (Fig.

12 2). After this period, FH6 left LGR and only came back six months later. All of the herds visited LGR during

13 both day and night with: 61\% (FH1), 67\% (FH3), 52\% (FH4), 57\% (FH5) and 49\% (FH6) of locations during

14 the day. Overall, none of the herds showed a preference with regards to the time of the day in which they visited

15 the LGR (Wilcoxon signed-rank test: $\mathrm{N}=5, \mathrm{~V}=14$, $\mathrm{p}$-value $=0.125$ ).

17 Home range shift

18 Before the fence was taken down, the home ranges of FH3, FH4 and FH5 were located primarily in the northern

19 part of the reserve (Fig. 4). However, during the wet season, all three of these home ranges expanded into the

20 South of the reserve. During both seasons, all of the herds' home ranges surrounded the LGR (Fig. 4). Despite

21 the seasonal changes in the home ranges, these home ranges overlapped between $65 \%$ and $79 \%$ (Table 4 .). One

22 year after the fence removal, all of the herds had incorporated LGR into their home ranges (Fig. 4). However,

23 there was no significant change in the overall size of either the dry or wet season home ranges after the fence

24 was taken down (Wilcoxon signed-rank test: dry home ranges, $\mathrm{V}=5, \mathrm{~N}=4$, p-value $=1$; wet home ranges, $\mathrm{V}=$

$254, \mathrm{~N}=4$, $\mathrm{p}$-value $=0.87)$. On average $81 \%( \pm 13 \%)$ of the previous wet season home ranges were still included

26 into the new wet season home ranges, and the mean overlapping between the previous and the new dry season

27 home ranges was $76 \%( \pm 16 \%)$ (Table 4$)$.

28 A year after the fence removal, despite few modifications in the percentages of vegetation types (e.g. the

29 cover of sandveld woodlands and sand forest increased. Supp. Appendix 3), the habitat composition of the wet 
1 and dry season home ranges had not significantly changed (Wilcoxon signed-rank test: dry-season habitat composition, $\mathrm{V}=13, \mathrm{~N}=7$, $\mathrm{p}$-value $=0.94$; wet home ranges, $\mathrm{V}=14, \mathrm{~N}=7$, $\mathrm{p}$-value $=1$ ).

Discussion

5 After the expansion of MYW, we observed a rapid expansion of the resident elephant breeding herds into the newly available LGR. The month following the opening, all of herds had visited LGR at least once, despite being more than $10 \mathrm{~km}$ from the fence when it was taken down. They explored the new section quickly and regularly during the wet season following the fence removal. After a year, all of the herds had incorporated the LGR into their home ranges and thus modified the habitat composition of their seasonal home ranges.

Our results contrast to those of Druce et al. (2007) who found that the exploration of new areas by the same

11 elephant herds took between four and eight months after the fence was removed. In our study, prior to the removal of the fence, the herds regularly visited the area in the vicinity of the fence, with a minimum of one visit every seven days. We also observed that when the average of the return time to the vicinity of LGR was short, the time taken to enter the new section was also short. This suggests that the frequent visits to the area next to the fence could have facilitated the rapid discovery of the newly opened area once the fence was taken down.

After the first entry, all herds continued to use LGR, and incorporated parts of it into their seasonal home ranges. The herds visited this section regularly, during both the day and night, at least every two days. In contrast, Druce et al. (2007) found that the same herds acted cautiously during their exploration of a new area. This was

19 indicated by the significant preference for exploring at night, and the fact that the longest exploration distance within the new area occurred only six to 12 months after the first entry.

Druce et al. (2007) tentatively explained this slow exploration by suggesting that the resources and space for the elephants in the previously available area were probably sufficient. In that study, however, the new area composed mostly mixed acacia woodlands (92\%), a habitat avoided by elephants in our study, and only $6 \%$ riparian, and $2 \%$ palm veld, two habitat types preferred by elephants. In our study, the LGR was mostly covered by sandveld woodlands and sand forest (62\%) and palm veld $(26 \%)$, which were strongly selected for by the elephants and the most available vegetation types in their previous seasonal home ranges (Supp. Appendix 4).

27 Thus, it is possible that the difference observed between Druce et al. (2007) and our study is the result of the preferred habitat composition of the newly available LGR attracting the elephants in our study. 
1 sizes of the home ranges, however, did not increase. Thus, the home ranges of the elephants shifted such that

2 they no longer used portions of their previous home ranges. Moreover, the habitat compositions of the seasonal

3 home ranges were also not modified after the fence removal.

4 Contrast between our results and those of Druce et al. (2007) indicate that the expansion of a protected area

5 can lead to variable animal exploration and utilisation of the newly available area. Previous studies have

6 demonstrated that a low exploration may be due to a high site fidelity of animals (e.g. de Knegt et al. 2010,

7 Linklater et al. 2010) driven by their condition (e.g. age. Switzer 1993) and exogenous environmental variables

8 (e.g. tree cover, nutritional quality, water proximity, etc. de Knegt et al. 2010). In addition, our findings suggest

9 that animals' habitat preferences likely define the attractiveness of new areas and thus might influence the

10 response they have towards area expansion. This is also likely true for the utilisation of newly established

11 corridors. Overall, there is a clear need to better understand the factors underlying site fidelity and exploration

12 behaviour.

13 Here we suggest that the quality of the habitat (as indexed by habitat selection) made available to the 14 elephants in the new section and the fact that the herds regularly used the area close to the fence, have facilitated 15 the rapid discovery and use of the LGR by all the herds. It may, however, simply be that the elephants incorporated the area as it is small (1,612 hectares) in relation to the elephant herds' seasonal home ranges (mean

17 wet and dry season home range sizes: $126.7 \mathrm{~km}^{2}$ and $107.4 \mathrm{~km}^{2}$ ). Yet, in the study by Druce et al. (2007), they found that in the same reserve, the elephants did not incorporate a small section $(3,850$ hectares $)$ that was opened

19 adjacent to the elephants' home ranges. The elephants visited this area a few month after the fence was removed

20 (Druce et al. 2007) but now 15 years down the line, they still have not incorporated it (see Fig. 4). This suggests

21 that the elephants likely use habitat quality as a key driver when utilising and incorporating newly available areas 22 and do not simply move into areas because they are available.

We, however, acknowledge that this remains a tentative explanation due to the very low sample size of the 24 study. This limitation was mostly imposed by the small size of the population, as virtually the whole female segment of the population was monitored. Yet, we believe that studies on rare and endangered species, for which area expansion might be critical, will often be constrained by population size and financial or logistical constraints. If so, the depth and robustness of our global knowledge will likely arise from the multiplicity of studies with small sample size like ours. We therefore call for publication of these studies, to avoid knowledge

29 loss due to file-drawer effects or publication in grey literature. Also, when possible, systematic reviews or 
comparison between very similar situations (like the comparison between our study and the one from Druce et al.

2007) may improve, or at least challenge, our understanding.

In human-modified landscape, space is a limiting factor for many animals, particularly for large wide-

ranging species such as elephants. The addition of space within protected areas is currently a common practice to try to overcome this, and thus to try to maintain a sustainable population and ecosystem. However, we do not know how successful these measures may be as we do not know how long it takes animals to find new areas. By suggesting what factors could have influenced the discovery and the use of a new area by elephants, our study join others to fill this research gap and thus to help protected area managers to reach their conservation aims.

References

Bangs EE and Fritts SH (1996) Reintroducing the gray wolf to central Idaho and Yellowstone National Park. Wildlife Society Bulletin 24, 402-413. Retrieved from www.wolfology.com. Accessed April 2019.

Biggs HC, Slotow R, Scholes B, Carruthers J, van Aarde R, Graham K, Twine W, Grobler D,

Cardillo M, Purvis A, Sechrest W, Gittleman JL, Bielby J and Mace GM (2004) Human Population Density and Extinction Risk in the World's Carnivores. PloS Biol 2, 909-914.

Chamaillé-Jammes S (2019) A reformulation of the selection ratio shed light on resource selection functions

de Knegt HJ, Pretorius Y, van Langevelde F, de Boer WF, Gort G, Skidmore AK, Slotow R, Henley S,

Douglas-Hamilton I, Krink T and Vollrath F (2005) Movements and corridors of African elephants in relation to protected areas. Naturwissenschaften 92, 158-163.

Druce HC, Pretorius K and Slotow R (2007) The response of an elephant population to conservation area expansion: Phinda Private Game Reserve, South Africa. Biol. Conserv. 141, 3127-3138.

30 Eastridge R and Clark JD (2001) Linked references are available on JSTOR for this article : Evaluation of 2 
soft-release techniques to reintroduce black bears. Wildl. Soc. Bull. (1973-2006) 29, 1163-1174. Retrieved from www.wolfology.com

Fryxell JM and Sinclair RE (1988) Seasonal migration by white-eared kob in relation to resources. Afr. J. Ecol. 26, 17-31.

\section{Getz WM, Fortmann-roe S, Cross PC, Lyons AJ, Ryan SJ and Wilmers CC (2007) LoCoH :} Nonparameteric Kernel Methods for Constructing Home Ranges and Utilization Distributions. PLoS ONE e207(2), 1-8.

Grant RC, Bengis RG, Balfour D, Peel MJS, Africa S and Mostert W (2008) Controlling the distribution of elephants. In Scholes RJ and Mennell KG (ed.), Elephant Management: A Scientific Assessment for South Africa. Wits University Press: Johannesburg, pp. 329-369.

Harris G, Thirgood S, Hopcraft JGC, Cromsigt JPGM and Berger J (2009) Global decline in aggregated migrations of large terrestrial mammals. Endangered Species Research 7, 55-76.

Larkin JL, Cox JJ, Wichrowski MW, Dzialak MR, Maehr DS (2004) Influences on Release-Site Fidelity of Translocated Elk. Restoration Ecol. 12, 97-105.

Linklater WL, Macdonald EA, Flamand JRB and Czekala NM (2010) Declining and low fecal corticoids are associated with distress, not acclimation to stress, during the translocation of African rhinoceros. Anim. Conserv. 13, 104-111.

Manly BFJ (2002) Estimating a Resource Selection Function With Line Transect Sampling. Journal of Appli. Math. Decis. Sci. 6, 213-228.

Mettke-Hofmann C, Winkler H and Leisler B (2002) The significance of ecological factors for exploration and neophobia in parrots. Ethol. 108, 249-272.

Mueller T, Olson KA, Dressler G, Leimgruber P, Fuller TK, Nicolson C, Novaro AJ, Bolgeri MJ, Wattles D, DeStefano S, Calabrese JM and Fagan WF (2011) How landscape dynamics link individual to population-level movement patterns : a multispecies comparison of ungulate relocation data. Glob. Ecol. Biog. 20, 683-694.

Naughton-treves L, Holland MB and Brandon K (2005) The role of protected areas in conserving biodiversity and sustaining local livelihoods. Annu. Rev. Env. Resour. 30, 219-252.

Osborn FV and Parker GE (2003) Linking two elephant refuges with a corridor in the communal lands of Zimbabwe. Afr. J. Ecol. 41, 68-74.

Owen-Smith RN (1988) Megaherbivores. The influence of very large body size on ecology. (Cambridge). 
Cambridge. Retrieved from http://dx.doi.org/10.1017/CBO9780511565441

2 Schmitt MH, Shuttleworth A, Ward D and Shrader AM (2018) African elephants use plant odours to make foraging decisions across multiple spatial scales. Anim. Behav. 141, 17-27.

4 Slotow R and Page B (2002) Preliminary Report on Elephant Vegetation Utilization at Phinda Resource Reserve.

6 Switzer PV (1993) Site fidelity in predictable and unpredictable habitats. Evol. Ecol. 7, 533-555.

7 Tucker MA, Böhning-gaese K, Fagan WF, Fryxell JM, van Moorter B, Alberts SC, ... Rimmler M (2018) Moving in the Anthropocene: Global reductions in terrestrial mammalian movements. Science 359, 466469.

van Moorter B, Bunnefeld N, Panzacchi M, Rolandsen CM, Solberg EJ and Saether BE (2013) Ecol. 82, 770-780.

13 


\section{$7 \quad$ Figure captions}

9 Fig. 1 Map of the Mun-Ya-Wana Conservancy. Each colour represents one of the three private game reserves

10 (i.e. Phinda Private Game Reserve, Zuka Private Game Reserve, Bumbeni) included into the Mun-Ya-Wana

11 Conservancy. The striped black polygon represents the Lulubush section added the $4^{\text {th }}$ of October 2017. During

12 the dry season, water can only be found in six dry season water points (black circles) and two non-perennial

13 rivers (black thick lines). The shaded area in the insert map is the KwaZulu-Natal province.

15 Fig. 2 Distance to the former fence estimated between two weeks before the fence removal and the end of the

16 wet season after the fence removal. Positive values represent locations within the newly available Lulubush

17 section, negative values represent locations within the area already accessible before the fence removal. The grey

18 polygon covers the two-week period before the fence removal.

20 Fig. 3 The relationship between the percentage of time spent within $100 \mathrm{~m}$ of the fence during the year before 21 the fence removal and the time taken for the elephant herds to move within the newly available Lulubush section.

22 The time taken to move is defined as the time from the fence removal to the first entry into Lulubush.

24 Fig. 4 Estimation of the breeding family herds' home ranges before the fence removal in the wet and dry seasons,

25 and after the fence removal in the wet and dry seasons. Home ranges were obtained by using the $\mathrm{k}-\mathrm{LoCoH}$ 26 method (90\% isopleth). 
1 Fig. 5 Selection ratios for the seven vegetation types (1-7) by the different elephant herds before the fence

2 removal in the wet (a) and dry (b) seasons. Each dot indicates the mean selection ratio of the corresponding

3 elephant herd for the seven vegetation types, with the associated confidence intervals (confidence limits: $2.5 \%$

4 and $97.5 \%$ ). When both limits of the confidence interval were different to 1 , we estimated a significative positive

5 selection (above) and a significative avoidance (below).

6

7 
1 Table 1. Time taken for the elephant herds to move into the newly available area, reported as information about

2 their use of the area within $100 \mathrm{~m}$ of the fence during the year before the fence removal.

3

\begin{tabular}{lcccc}
\hline Family Herds & $\begin{array}{c}\text { Time from fence } \\
\text { removal to first } \\
\text { entry into new area } \\
\text { (days) }\end{array}$ & $\begin{array}{c}\text { Proportion of time spent } \\
\text { within } 100 \mathrm{~m} \text { of the } \\
\text { fence } \\
(\%)\end{array}$ & $\begin{array}{c}\text { Return time (days) } \\
\text { within } 100 \mathrm{~m} \text { of the } \\
\text { fence, dry season } \\
\text { (mean } \pm \text { s.d.) }\end{array}$ & $\begin{array}{c}\text { Return time (days } \\
\text { within } 100 \mathrm{~m} \text { of the } \\
\text { fence, }\end{array}$ \\
$\begin{array}{l}\text { wet season } \\
\text { (mean } \pm \text { s.d.) }\end{array}$ \\
FH1 & 9 & - & - & - \\
FH3 & 13 & 0.6 & $19.1 \pm 22.4$ & 170 \\
FH4 & 5 & 2.0 & $6.8 \pm 9.1$ & 17.9 \\
FH5 & 9 & 1.3 & $10.1 \pm 13.3$ & $20.6 \pm 35.8$ \\
FH6 & 34 & 0.1 & - & - \\
\hline
\end{tabular}

4

5

6

7

8

9

10

11

12

13

14

15

16

17

18

19

20

21

22

23 
1 Table 2. Maximum distance travelled into the newly available area during the initial exploration by each of the

2 elephant herd. In addition, we report the maximum distance travelled into the new area during the year following

3 the fence removal, and the number of days after fence removal when this occurred.

4

\begin{tabular}{lccc}
\hline Family Herds & $\begin{array}{c}\text { Maximum distance } \\
\text { travelled during initial } \\
\text { entry } \\
(\mathrm{m})\end{array}$ & $\begin{array}{c}\text { Duration of time } \\
\text { before the greatest } \\
\text { distance moved } \\
(\text { month })\end{array}$ & $\begin{array}{c}\text { Maximum distance } \\
\text { travelled into the new } \\
\text { area } \\
(\mathrm{m})\end{array}$ \\
\hline FH1 & 508 & 8.5 & 3,477 \\
FH3 & 672 & 8.7 & 3,439 \\
FH4 & 313 & 7.3 & 3,487 \\
FH5 & 278 & 5.5 & 3,388 \\
FH6 & 1,428 & 9.0 & 3,321 \\
\hline
\end{tabular}

5

6

7

8

9

10

11

12

13

14

15

16

17

18

19

20

21

22

23 
1 Table 3. Size of the seasonal home ranges of each elephant herd estimated before and after the fence removal. In

2 addition, we report the estimation of the overlap between seasonal home ranges for each elephant herd. WHR

3 and DHR refer to wet and dry season home ranges respectively.

4

\begin{tabular}{|c|c|c|c|c|c|c|c|c|c|}
\hline \multirow{2}{*}{$\begin{array}{c}\text { Family } \\
\text { Herds }\end{array}$} & $\begin{array}{c}\text { Size } \\
\text { WHR }\end{array}$ & $\begin{array}{l}\text { Size } \\
\text { DHR }\end{array}$ & $\begin{array}{c}\text { Size } \\
\text { WHR }\end{array}$ & $\begin{array}{l}\text { Size } \\
\text { DHR }\end{array}$ & WHR/DHR & $\begin{array}{c}\text { Pre } \\
\text { WHR/ } \\
\text { Post } \\
\text { WHR }\end{array}$ & $\begin{array}{c}\text { Pre } \\
\text { DHR/ } \\
\text { Post } \\
\text { WHR }\end{array}$ & $\begin{array}{c}\text { Pre } \\
\text { WHR/ } \\
\text { Post } \\
\text { DHR }\end{array}$ & $\begin{array}{c}\text { Pre } \\
\text { DHR/ } \\
\text { Post } \\
\text { DHR }\end{array}$ \\
\hline & $\begin{array}{c}\text { Pre- } \\
\text { opening } \\
\left(\mathrm{km}^{2}\right)\end{array}$ & $\begin{array}{c}\text { Pre- } \\
\text { opening } \\
\left(\mathrm{km}^{2}\right)\end{array}$ & $\begin{array}{c}\text { Post- } \\
\text { Opening } \\
\left(\mathrm{km}^{2}\right)\end{array}$ & $\begin{array}{c}\text { Post- } \\
\text { Opening } \\
\left(\mathrm{km}^{2}\right)\end{array}$ & $\begin{array}{c}\text { Overlap } \\
\text { Pre- } \\
\text { opening } \\
(\%)\end{array}$ & $\begin{array}{c}\text { Overlap } \\
(\%)\end{array}$ & $\begin{array}{c}\text { Overlap } \\
(\%)\end{array}$ & $\begin{array}{c}\text { Overlap } \\
(\%)\end{array}$ & $\begin{array}{c}\text { Overlap } \\
(\%)\end{array}$ \\
\hline FH3 & 139.3 & 117.1 & 127.9 & 100.3 & 68.8 & 72.9 & 82.0 & 54.1 & 76.5 \\
\hline FH4 & 141.1 & 101.3 & 99.4 & 97.4 & 65.3 & 71.5 & 82.9 & 53.1 & 96.7 \\
\hline FH5 & 153.9 & 115.2 & 155.3 & 100.8 & 73.4 & 80.2 & 88.5 & 54.0 & 69.7 \\
\hline FH6 & 72.5 & 96.1 & 124.4 & 126.5 & 79.4 & 100 & 95.2 & 98.7 & 59.9 \\
\hline
\end{tabular}

Selected values for $\mathrm{k}$ for home ranges computation (see text for details):

- $\quad$ for WHR pre-opening: FH3 39.5 / FH4 43.5 / FH5 45.5 / FH6 40.0

- $\quad$ for DHR pre-opening: FH3 35.0 / FH4 40.5 / FH5 36.5 / FH6 36.5

- $\quad$ for WHR post-opening: FH3 45.0 / FH4 46.5 / FH5 42.5 / FH6 37

- $\quad$ for DHR post-opening: FH3 42.0 / FH4 38.0 / FH5 42.5 / FH6 33.0

5

6

7

8

9

10

11

12

13

14

15

16

17

18

19

20

21

22 
Elephants' response to an area expansion

1

3

4

6

7

8

9

11

12

13

14

15

16

17

18

19

20

21

22

23

24

25

26

27

28

29

30

31

32

33

34

35

36

37

38

39

40

41

42

43

44

45

46

47

48

49

50

51

52

53

54

55

56

57

58

59

60

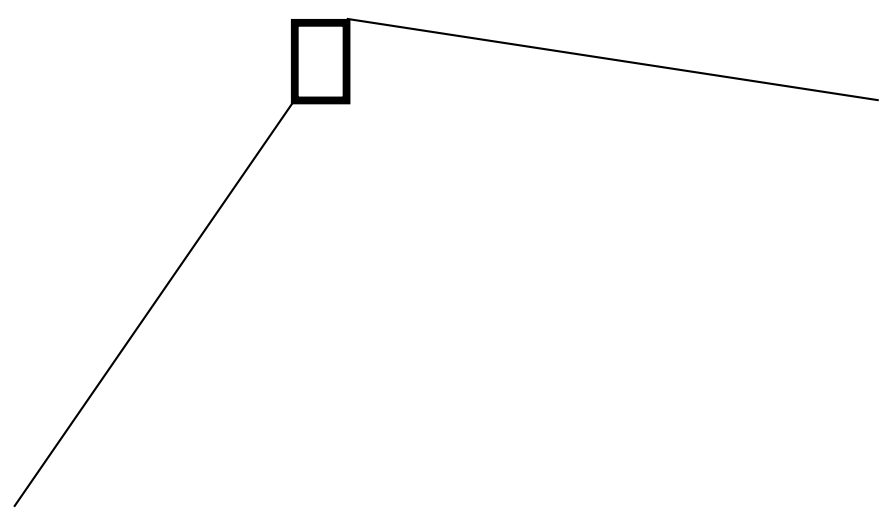

Fig. 1 
Elephants' response to an area expansion

1

2

3

35

36 


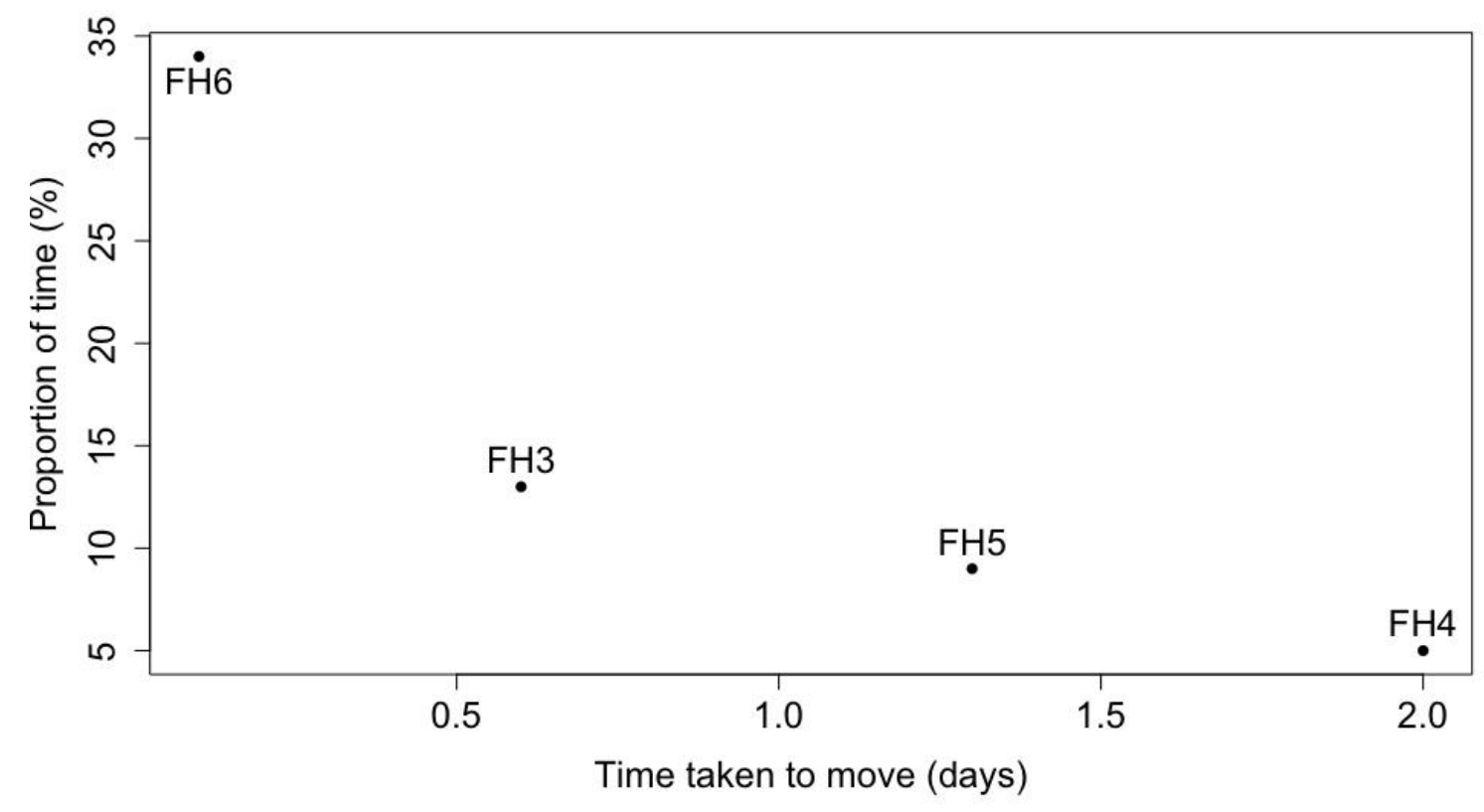

Fig. 3 


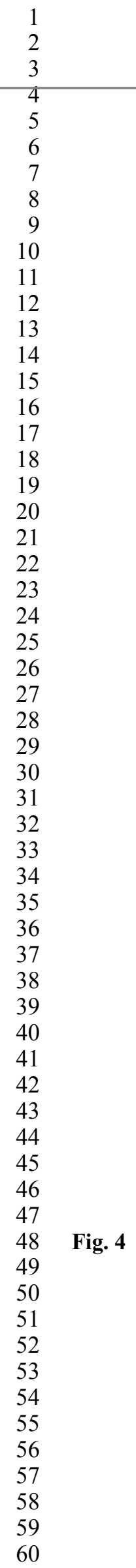


Elephants' response to an area expansion

1

2

3

4

6

7

8

9 Fig. 5

10

11

12

13

14

15

16

17

18

19

20 
4 Supplementary material 1. Vegetation map of the Mun-Ya-Wana conservancy. 5

6 Vegetation types
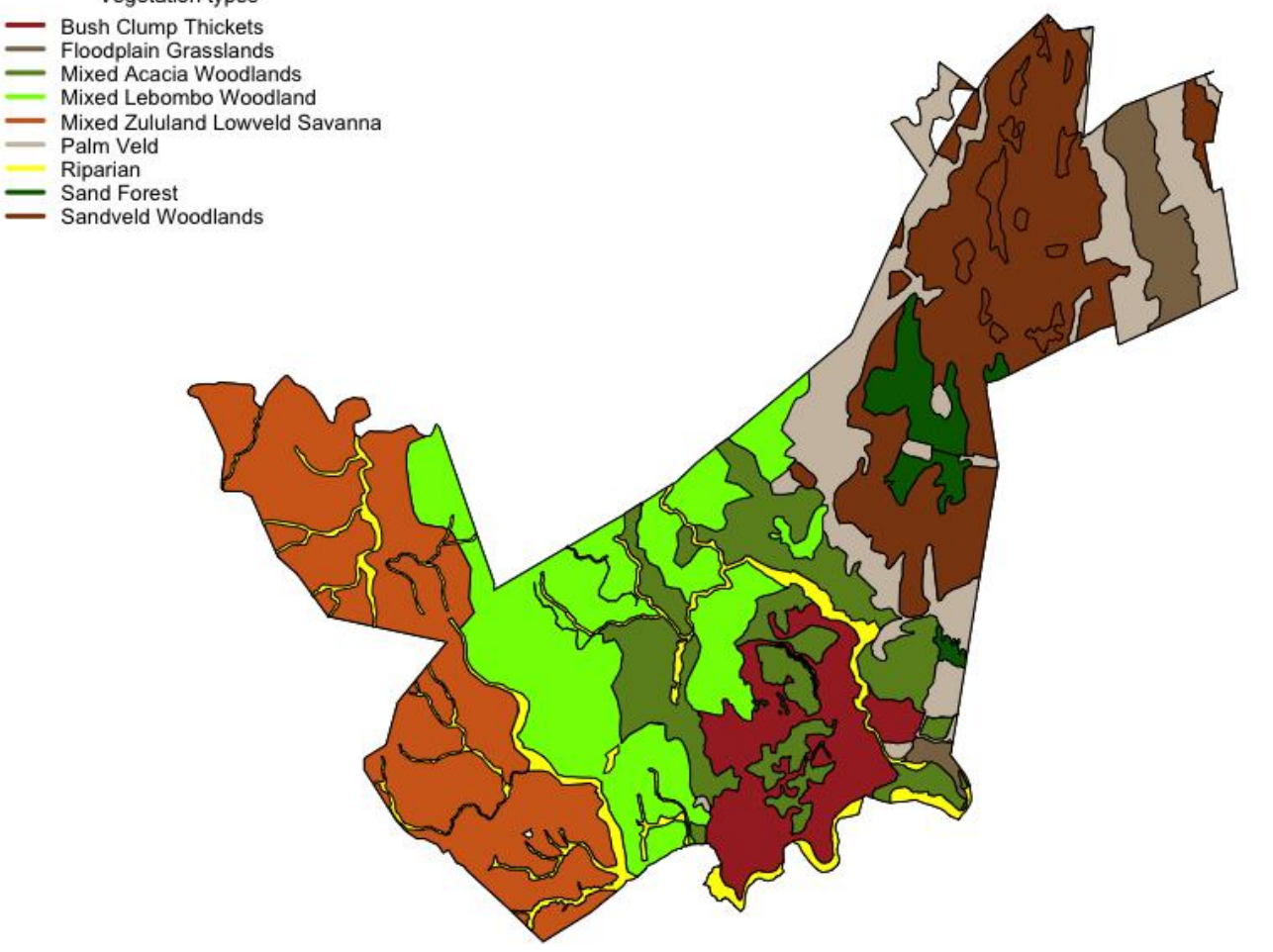
2 Supplementary material 2. Percentage of locations acquired at most $30 \mathrm{~min}$ apart and that are at least 250 meters

3 apart, for each possible pair of elephant herds. The first line presents calculations made from data collected

4 during the year before the fence. The second and third lines present calculations made from data collected during

5 the dry and the wet seasons respectively, following the fence removal.

6

7

\begin{tabular}{lcccccccccc}
\hline & FH2 / & FH2 / & FH2 / & FH2 / & FH3 / & FH3 / & FH3 / & FH4 / & FH4 / & FH5 / \\
& FH3 & FH4 & FH5 & FH6 & FH4 & FH5 & FH6 & FH5 & FH6 & FH6 \\
\hline $\begin{array}{l}\text { The whole } \\
\text { year }\end{array}$ & 1.3 & 15.5 & 68.9 & 0 & 2.2 & 2.0 & 1.1 & 14.1 & 0 & 0 \\
\hline Wet season & 11.0 & 14.3 & 81.7 & 0.2 & 0 & 13.0 & 1.0 & 12.6 & 0.6 & 0 \\
\hline Dry season & 19.0 & 10.2 & 78.9 & 0.9 & 12.9 & 17.4 & 0 & 14.0 & 4.7 & 1.9 \\
\hline
\end{tabular}

9

10

11

12

13

14

15

16

17

18

19

20

21

22

23

24

25

26

27

28

29

30

31

32

33

34

35

36

37

38

39

40

41

42

43

44

45

46

47

48

49

50

51

52
Supplementary material 3. Percentages of each vegetation type with the elephant herds' seasonal home ranges (wet and dry), before and after the fence removal. 
1

2

\begin{tabular}{|c|c|c|c|c|c|c|c|c|}
\hline \multicolumn{9}{|c|}{ Pre-opening } \\
\hline & $\begin{array}{l}\text { Family } \\
\text { herds }\end{array}$ & $\begin{array}{l}\text { Palm } \\
\text { Veld }\end{array}$ & $\begin{array}{c}\text { Mixed } \\
\text { Acacia } \\
\text { Lebombo } \\
\text { Woodlands }\end{array}$ & $\begin{array}{l}\text { Floodplain } \\
\text { Grassland }\end{array}$ & $\begin{array}{c}\text { Buch } \\
\text { Clump } \\
\text { Thicket }\end{array}$ & $\begin{array}{c}\text { Mixed } \\
\text { Zululand } \\
\text { Lowveld } \\
\text { Savanna }\end{array}$ & Riperian & $\begin{array}{c}\text { Sand Forest } \\
\text { and } \\
\text { Sandveld } \\
\text { Woodlands }\end{array}$ \\
\hline & FH3 & 19.3 & 23.9 & 6.4 & 2.3 & 10.9 & 3.9 & 33.1 \\
\hline Wet & FH4 & 19.2 & 18.8 & 7.1 & 2.7 & 11.9 & 3.9 & 36.3 \\
\hline \multirow[t]{2}{*}{ Season } & FH5 & 18.8 & 14.8 & 5.8 & 9.6 & 9.4 & 5.2 & 36.3 \\
\hline & FH6 & 0.6 & 75.9 & 0 & 1.4 & 14.8 & 7.1 & 0 \\
\hline Dry & FH3 & 23.6 & 19.3 & 7.0 & 2.2 & 0 & 2.6 & 45.2 \\
\hline \multirow[t]{3}{*}{ Season } & FH4 & 20.7 & 11.4 & 6.4 & 9.1 & 0 & 2.6 & 49.7 \\
\hline & FH5 & 19.4 & 15.3 & 3.4 & 15.1 & 0 & 2.3 & 44.5 \\
\hline & FH6 & 7.1 & 65.1 & 0 & 19.8 & 0.2 & 5.2 & 2.6 \\
\hline
\end{tabular}

Post-opening

\begin{tabular}{lcccccccc} 
Wet & FH3 & 17.4 & 18.3 & 6.2 & 3.5 & 5.7 & 4.1 & 44.6 \\
Season & FH4 & 22.7 & 12.0 & 6.6 & 9.9 & 0 & 2.1 & 46.5 \\
& FH5 & 25.5 & 8.2 & 8.1 & 1.2 & 0 & 1.3 & 55.6 \\
& FH6 & 10.6 & 52.1 & 0 & 2.8 & 12.9 & 5.9 & 15.8 \\
Dry & FH3 & 24.0 & 8.4 & 8.3 & 5.9 & 0 & 2.0 & 51.4 \\
Season & FH4 & 24.6 & 9.0 & 7.5 & 4.1 & 0 & 1.6 & 53.1 \\
& FH5 & 25.2 & 8.1 & 7.1 & 1.8 & 0 & 1.4 & 56.4 \\
& FH6 & 7.9 & 43.5 & 0 & 5.3 & 24.3 & 6.1 & 12.9 \\
\hline
\end{tabular}

5

6

7

8

9

10

11

12

13

14

15

16

17

18

19

20

21

22

23

24

25

26

27

28

29

30

31

32

33 
1 Supplementary material 4. Proportions of availability of each vegetation type within the elephant herds' seasonal 2 home ranges, before the fence removal.

3

4

\begin{tabular}{lcccccccc}
\hline & $\begin{array}{c}\text { Family } \\
\text { herds }\end{array}$ & $\begin{array}{c}\text { Palm } \\
\text { Veld }\end{array}$ & $\begin{array}{c}\text { Mixed } \\
\text { Acacia } \\
\text { Lebombo } \\
\text { Woodlands }\end{array}$ & $\begin{array}{c}\text { Floodplain } \\
\text { Grassland }\end{array}$ & $\begin{array}{c}\text { Buch } \\
\text { Clump } \\
\text { Thicket }\end{array}$ & $\begin{array}{c}\text { Mixed } \\
\text { Zululand } \\
\text { Lowveld } \\
\text { Savanna }\end{array}$ & $\begin{array}{c}\text { Riperian } \\
\text { Fond } \\
\text { Forest and } \\
\text { Sandveld } \\
\text { Woodlands }\end{array}$ \\
\cline { 2 - 9 } Wet & FH3 & 18.2 & 25.3 & 6.4 & 2.2 & 11.0 & 4.2 & 32.5 \\
Season & FH4 & 19.4 & 19.3 & 7.3 & 2.9 & 11.9 & 3.8 & 35.4 \\
& FH6 & 18.9 & 15.7 & 5.8 & 9.9 & 9.3 & 4.8 & 35.4 \\
Dry & FH3 & 23.9 & 20.3 & 7.4 & 2.2 & 0 & 2.7 & 43.4 \\
& FH4 & 20.7 & 11.2 & 6.7 & 9.6 & 0 & 2.6 & 49.1 \\
& FH5 & 19.4 & 15.7 & 3.8 & 15.6 & 0 & 2.2 & 43.3 \\
\hline
\end{tabular}

